\title{
Next-Generation Sequencing Reveals Four Novel Viruses Associated with Calf Diarrhea
}

\author{
Qi Wu 1,2, ${ }^{\text {, Jizong Li 1,3,4,5, }}$, Wei Wang 1,3,4,5, ${ }^{\dagger}$, Jinzhu Zhou 1,3,4,5, Dandan Wang 1,3,4,5, Baochao Fan 1,3, \\ Xuehan Zhang ${ }^{1,3}$, Dongbo Sun ${ }^{6}$, Ga Gong ${ }^{2, *}$, Sizhu Suolang ${ }^{2, *}$ and Bin Li 1,3,4,5,*
}

1 Institute of Veterinary Medicine, Jiangsu Academy of Agricultural Sciences, Key Laboratory of Veterinary Biological Engineering and Technology Ministry of Agriculture, Nanjing 210014, China; wuqi1109323413@163.com (Q.W.); lijizong22@sina.com (J.L.); 13952032293@126.com (W.W.); syzhoujz@163.com (J.Z.); wddan26@163.com (D.W.); fanbaochao.0405@163.com (B.F.); liuxuehan1996@hotmail.com (X.Z.)

2 Animal Science College, Tibet Agriculture and Animal Husbandry University, Nyingchi 860000, China

3 Jiangsu Key Laboratory for Food Quality and Safety-State Key Laboratory Cultivation Base of Ministry of Science and Technology, Nanjing 210014, China

4 Jiangsu Co-Infection Center for Prevention and Control of Important Animal Infectious Disease and Zoonoses, Yangzhou 225009, China

5 Jiangsu Key Laboratory of Zoonoses, Yangzhou University, Yangzhou 225009, China

6 Laboratory for the Prevention and Control of Swine Infectious Diseases, College of Animal Science and Veterinary Medicine, Heilongjiang Bayi Agricultural University, Daqing 163319, China; dongbosun@126.com

* Correspondence: xzlzgg@163.com (G.G.); xzslsz@163.com (S.S.); libinana@126.com (B.L.)

+ These authors contributed equally to this work.

Citation: Wu, Q.; Li, J.; Wang, W.; Zhou, J.; Wang, D.; Fan, B.; Zhang, X.; Sun, D.; Gong, G.; Suolang, S.; et al. Next-Generation Sequencing Reveals Four Novel Viruses Associated with Calf Diarrhea. Viruses 2021, 13, 1907. https://doi.org/10.3390/v13101907

Academic Editors: Leyi Wang and Ganwu Li

Received: 29 July 2021

Accepted: 17 September 2021

Published: 23 September 2021

Publisher's Note: MDPI stays neutral with regard to jurisdictional claims in published maps and institutional affiliations.

Copyright: (c) 2021 by the authors. Licensee MDPI, Basel, Switzerland. This article is an open access article distributed under the terms and conditions of the Creative Commons Attribution (CC BY) license (https:/ / creativecommons.org/licenses/by/ $4.0 /)$.
Abstract: Calf diarrhea is one of the common diseases involved in the process of calf feeding. In this study, a sample of calf diarrhea that tested positive for bovine coronavirus and bovine astrovirus was subjected to high-throughput sequencing. The reassembly revealed the complete genomes of bovine norovirus, bovine astrovirus, bovine kobuvirus, and the $\mathrm{S}$ gene of bovine coronavirus. Phylogenetic analysis showed that the ORF2 region of bovine astrovirus had the lowest similarity with other strains and gathered in the Mamastrovirus unclassified genogroup, suggesting a new serotype/genotype could appear. Compared with the most closely related strain, there are six amino acid mutation sites in the $\mathrm{S}$ gene of bovine coronavirus, most of which are located in the S1 subunit region. The bovine norovirus identified in our study was BNoV-GIII 2, based on the VP1 sequences. The bovine kobuvirus is distributed in the Aichi virus B genus; the P1 gene shows as highly variable, while the $3 \mathrm{D}$ gene is highly conserved. These findings enriched our knowledge of the viruses in the role of calf diarrhea, and help to develop an effective strategy for disease prevention and control.

Keywords: next-generation sequencing; genome analysis; calf diarrhea; bovine kobuvirus; bovine norovirus; bovine astrovirus; bovine coronavirus

\section{Introduction}

Calf diarrhea is a common gastrointestinal disease in calves, and most cases occur at less than 1 month of age. Calf diarrhea often occurs due to environmental contamination with pathogens, and it is transmitted via fecaoral transmission routes. The main clinical features include diarrhea, dehydration, and foul-smelling feces. Morbidity and mortality are high, and the incidence of calf diarrhea was higher when cattle were raised in groups [1] Prior studies have implicated several viruses in calf diarrhea, and rotavirus is the main viral causative agent of diarrhea in calves worldwide [2]. Moreover, several other viruses, including bovine viral diarrhea virus (BVDV), bovine adenovirus (BAdV), bovine torovirus $(\mathrm{BToV})$, bovine parvovirus (BPV), bovine coronavirus (BCoV), bovine astrovirus (BoAstV), bovine kobuvirus (BKoV), and bovine norovirus (BNoV), have been recognized as the causative agents of diarrhea [3-7]. The economic impact caused by this condition is 
significant, although many new intervention strategies, such as vaccines, medications, and herd management, have been developed and implemented to minimize economic losses [8].

A metagenomic approach was used to detect all potential pathogens in a sample, this method has great potential utility in the diagnosis of infectious disease $[9,10]$. The traditional diagnostic techniques in laboratories include viral culture and the molecular identification of viral nucleic acids, most commonly via PCR/RT-PCR. Most molecular assays target only a limited number of pathogens using specific primers or probes, while metagenomic approaches characterize all DNA or RNA present in a sample, enabling the analysis of an entire genome. The metagenomic approach for clinical applications derives its roots from the use of microarrays in the early 2000s [11,12]; these methods have been widely used to identify infections in ancient remains [13], characterize the animal virome in both healthy and diseased states [14,15], and discover novel viral pathogens [16].

In February 2021, calf diarrhea of unknown pathogen broke out on a cattle farm in Shijiazhuang, Hebei province, China. We collected 63 cases of diarrheal calf stool and sent it to the laboratory for pathogen detection. Several diagnostic methods were performed, including the RT-PCR assay, to detect BVDV, BCoV, BoAstV, and BRoV. The results show that there are a large number of mixed infections, and, as we want to further explore the pathogens of mixed infections, the metagenomics were used to detect the unknown pathogens.

\section{Materials and Methods}

\subsection{Samples and RT-PCR Assays}

Sixty-three calf diarrhea samples from Shijiazhuang, Heibei Province, manifesting as weakness, fever, excretion of watery feces, and accompanied by a foul smell, were subjected to RNA extraction using HiPure Total RNA Mini Kit (AnGen, Guangzhou, China). The total RNA was further reverse transcribed into cDNA using a Vazyme Reverse Transcription Kit (Vazyme, Nanjing, China). PCR amplification was performed using $2 \times$ Taq Master Mix (Vazyme, Nanjing, China) with the following primers: For BVDV: sense, 5'-AGCGGGGATAAGGTTGGAAA-3'; antisense, 5' ${ }^{\prime}$-ACCTGCAGCCCCTTTTCTAT- ${ }^{\prime}$. For BCoV: sense, $5^{\prime}$-GCTACCAATTATTTTGCTTGGC-3'; antisense, $5^{\prime}$-ATGGAGAGGGCACA GACTTATC-3' ${ }^{\prime}$. For BoAstV: sense, 5'-GAYTGGACBCGHTWTGATGG-3'; antisense, 5'-K YTTRACCCACATNCCAA-3' . For BRoV: sense, $5^{\prime}$-ACCACCAAATATGACACCAGC-3'; antisense, 5'-CATGCTTCTAATGGAAGCCAC-3' (Genscript, Nanjing, China). The above four pairs of primers were designed with reference to sequences GenBank accession no. KF501393, LC494178, LC047787, and MZ540977, respectively, using the Primer Premier 5.0 software package. The PCR reactions were performed with $2 \mu \mathrm{L}$ of cDNA templates added to $18 \mu \mathrm{L}$ of reaction mixture, containing final concentrations of $0.5 \mu \mathrm{M}$ of each primer. The cDNA was amplified by 35 cycles of denaturation at $95^{\circ} \mathrm{C}$ for $30 \mathrm{~s}$, annealing at $55^{\circ} \mathrm{C}$ for $35 \mathrm{~s}$, and extension at $72{ }^{\circ} \mathrm{C}$ at $1 \mathrm{~kb} / \mathrm{min}$, and finally extended at $72{ }^{\circ} \mathrm{C}$ for $10 \mathrm{~min}$.

\subsection{Next Generation Sequencing (NGS)}

One RNA sample positive for both $\mathrm{BCoV}$ and $\mathrm{BoAstV}$ was selected and sent to Shanghai Tanpu Biotechnology Co., Ltd. (Shanghai, China) for next-generation sequencing to obtain the sequences of these two viruses and to explore whether there were other viruses that may cause calf diarrhea. We used Illumina sequencing technology to complete the genome amplification and in-depth sequencing of the virus strain. Subsequent DNase treatment and cleanup was followed by second-strand synthesis before library preparation using Nextera XT reagents and sequencing on the NovaSeq 6000 (Illumina). Read quality trimming was performed using the Skewer, with an additional trimming filter for unreliable sequences after a user-specified quality score. Host read subtraction by read-mapping was performed with the BWASW program against ribosomal RNAs $(16,18,23,28$, 5S, and internal transcribed spacers rRNA were retrieved from https:/ / www.ncbi.nlm.nih.gov/, accessed on 15 March 2021), bacterial genome sequences, and the latest host organism genome sequences. We then used SPAdes and MEGAHIT software to de novo assemble 
the reads obtained after removal of the above-mentioned contamination sequence. The de novo assembly followed the A5-miseq pipeline. The final scaffolds were subjected to bwasw read mapping and a mega blast homology search against the NCBI NT database.

\subsection{Completing the Sequence at Both Ends of the Genome}

The sequences of the spliced BoAstV and BNoV were compared at the NCBI website (https://www.ncbi.nlm.nih.gov/, accessed on 25 April 2021), which showed that they had the highest sequence similarity to LC047787 and MN480761, respectively. Therefore, they were used as templates to design primers to amplify both ends of the whole genome of the virus. For BoAstV-5': sense, 5'-CCAAAACAGGTCGGATTGAA-3'; antisense, 5' TAGCTATTAAGACGACAGCT-3'. For BoAstV-3': sense, $5^{\prime}$-GCATTAAGTTTAAGGCAGG C-3'; antisense, $5^{\prime}$ - CCCCTTCACCTATGCTAATCA- ${ }^{\prime}$. For BNoV-5' : sense, $5^{\prime}$-GTGAATGA AGACTTTGACGA-3'; antisense, $5^{\prime}$-AGGCCACGCGCCACCACGCT-3'. For BNoV -3' sense, 5' -TGGAGTTGCAGGCTCGCTCT-3'; antisense, $5^{\prime}$-AACAATGCTGAATAGGAGGC$3^{\prime}$. The BKoV and BCoV-S sequences were directly spliced by Illumina sequencing without amplification at both ends by RT-PCR methods.

\subsection{Phylogenetic and Genome Analysis}

We used the ORF Finder (https:/ / www.ncbi.nlm.nih.gov/, accessed on 12 May 2021) to predict open reading frames (ORFs) and their derived amino acid sequences. This method uses Clustal W software MEGA7.0 until genomic nucleotide sequences are aligned. Using the neighbor-joining method (neighbor-joining method, NJ), a phylogenetic tree was constructed, and an exhibit values (on Bootstrap) test was set to repeat 1000 times. At the same time, MegAlign software in the DNAstar software package was used to analyze the homology between these nucleotide sequences.

\section{Results}

\subsection{Identification of BCoV and BoAstV Infection in Feces Samples by RT-PCR}

The results showed that, in 48 samples out of 63 samples, at least one pathogen was detected, and the $\mathrm{BCoV}$ positive detection rate was the highest at $48.39 \%$, followed by BRoV (26.98\%), BoAstV (25.81\%), and BVDV (19.05\%). There are six types of mixed infections, $\mathrm{BVDV}+\mathrm{BCoV}, \mathrm{BVDV}+\mathrm{BoAst} \mathrm{V}, \mathrm{BCoV}+\mathrm{BRoV}, \mathrm{BCoV}+\mathrm{BoAstV}, \mathrm{BVDV}+\mathrm{BCoV}+\mathrm{BoAstV}$, $\mathrm{BCoV}+\mathrm{BRoV}+\mathrm{BoAstV}$, and the infection rate is as high as $46.03 \%$ (Table 1). In addition, we detected two different $\mathrm{BCoV}$ sequences. $\mathrm{BCoV}$ and $\mathrm{BoAst} V$ were detected in the mixed infection sample numbered 210,041, therefore the high-quality total RNA was subsequently used for the following deep sequencing.

Table 1. Detection of viruses in calves showing diarrhea.

\begin{tabular}{|c|c|c|c|c|c|c|c|c|c|c|c|c|c|c|c|c|}
\hline & \multicolumn{4}{|c|}{ Total Infection } & \multicolumn{5}{|c|}{ Single Infection } & \multicolumn{7}{|c|}{ Mixed Infection } \\
\hline & $a^{*}$ & $\mathbf{b}^{*}$ & $c^{*}$ & $d^{*}$ & a & b & c & d & Total & $a+b$ & $a+d$ & $b+c$ & $b+d$ & $\begin{array}{c}a+b+ \\
d\end{array}$ & $\begin{array}{c}b+c+ \\
d\end{array}$ & Total \\
\hline $\begin{array}{c}\text { Number of Positive } \\
\text { Detections }\end{array}$ & 12 & 30 & 17 & 16 & 2 & 10 & 5 & 2 & 19 & 7 & 3 & 11 & 1 & 6 & 1 & 29 \\
\hline $\begin{array}{l}\text { Positive Infection } \\
\text { Rate }(\%)\end{array}$ & 19.05 & 48.39 & 26.98 & 25.81 & 3.17 & 15.87 & 7.94 & 3.17 & 30.16 & 11.11 & 4.76 & 17.46 & 1.59 & 9.52 & 1.59 & 46.03 \\
\hline
\end{tabular}

*a: BVDV; b: BCoV; c: BRoV; d: BoAstV.

\subsection{Viral Metagenomics}

We extracted RNA from stool samples that tested positive for BoAstV and BCoV pathogens and then processed them for viral metagenomics using the Illumina HiSeq platform. The largest portion of the reads were assigned to the families Picornaviridae $(n=2992)$, Astroviridae $(n=819)$, and Caliciviridae $(n=187)$. We then generated complete or partial genome sequences for a subset of these viruses (Table 2). 
Table 2. Genomic information of the four viruses.

\begin{tabular}{cccccc}
\hline Virus & Species & GenBank Accession No. & Base Size (nt) & Amino Acid Size (aa) & GC (\%) \\
\hline BNoV/CN/HB-SJZ/2021 & Norovirus GIII.2 & MZ573179 & $7316(7276) *$ & 2488 & 57.50 \\
BoAstV/CN/HB-SJZ/2021 & $\begin{array}{c}\text { Mamastrovirus } \\
\text { Unclassified }\end{array}$ & Genogroup & MZ603733 & $6324(6284) *$ & 1965 \\
BKoV/CN/HB-SJZ/2021 & Aichivirus B & MZ603734 & 8376 & 52.25 \\
BCoV-S/CN/HB-SJZ/2021 & Embecovirus & MZ603735 & 4092 & 2568 & 1363 \\
\hline
\end{tabular}

* The sequence exclude the primer binding regions.

\subsection{Discovery and Analysis of BNoV}

$\mathrm{BNoV} / \mathrm{CN} / \mathrm{HB}-\mathrm{SJZ} / 2021$ genomic RNA consists of 7316 nucleotides. The BNoV genome contains three sequential ORFs starting from the $22 \mathrm{nt}$ : ORF1, 5055 (22-5076) nt; ORF2, 1569 (5063-6631) nt; ORF3, 849 (6423-7271) nt, all of which encode a nonstructural polyprotein and structural VP1 and VP2 proteins, respectively. The G $+\mathrm{C}$ content of our strain genome was $57.50 \%$, similar to that of the B309 (56.96\%) and Newbury2 $(56.71 \%)$ strains. Homology analysis shows that BNoV/CN/HB-SJZ/2021 and the NoravusGIII virus (MN480761) have 93.4\% nucleotide characteristics (Table 3). Phylogenetic tree analysis shows the closest relationship with MN480761 (Figure 1a), as well as genetic evolution analysis, revealing that the VP1 protein is located in the same branch as the GIII.2 subtype (Figure 1b). Further analysis of the genetic evolutionary tree shows that the RdRp region of the virus also has the closest genetic relationship with MN480761 (Figure 1c).
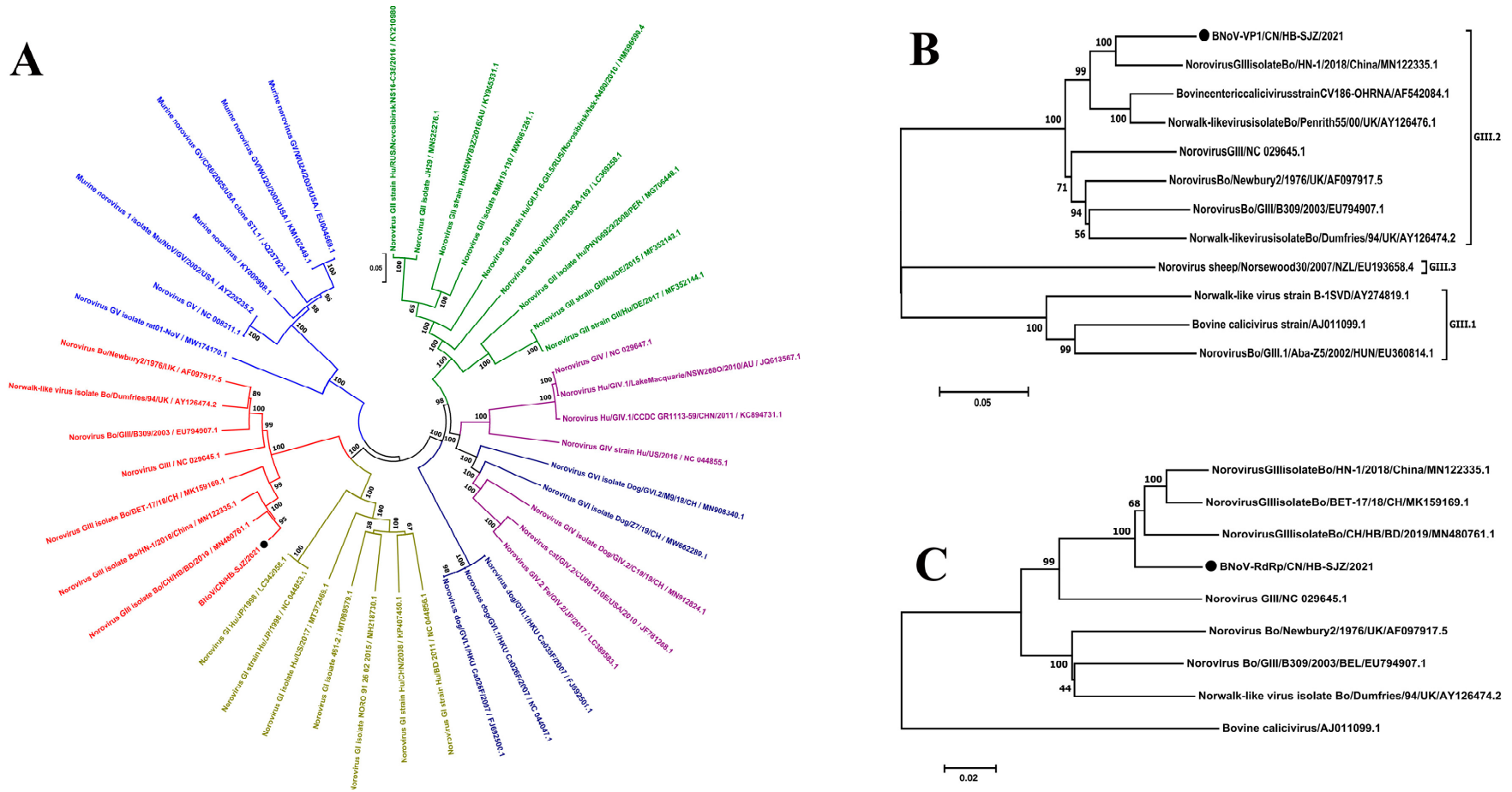

Figure 1. Phylogenetic analysis of BNoV/CN/HB-SJZ/2021: (A) Neighbor-joining unrooted phylogenetic trees based on the nucleotide sequences of the complete genomes of BNoV/CN/HB-SJZ/2021 and other genotypes. (B) Neighborjoining unrooted phylogenetic trees based on the VP1 gene sequences of BNoV/CN/HB-SJZ/2021 and other GIII subtypes. (C) Neighbor-joining unrooted phylogenetic trees based on the RdRp gene sequences of BNoV/CN/HB-SJZ/2021 and other GIII subtypes. The bar represents a genetic distance. Numbers at nodes indicate bootstrap percentages obtained after 1000 bootstrap replicates. Our strain, BNoV/CN/HB-SJZ/2021, is marked with a black circle $(\bullet)$. 
Table 3. The nucleotide identities of $\mathrm{BNoV} / \mathrm{CN} / \mathrm{HB}-\mathrm{SJZ} / 2021$ compared to different norovirus isolates.

\begin{tabular}{|c|c|c|c|c|c|c|}
\hline \multicolumn{7}{|c|}{ Nucleotide Identity (\%) } \\
\hline & $\begin{array}{c}\text { Norovirus GI } \\
\text { (MT372469) } \\
\text { Human }\end{array}$ & $\begin{array}{c}\text { Norovirus GII } \\
\text { (KY210980) } \\
\text { Human }\end{array}$ & $\begin{array}{c}\text { Norovirus GIII } \\
\text { (MN480761) } \\
\text { Cattle }\end{array}$ & $\begin{array}{c}\text { Norovirus GIV } \\
\text { (NC029647) } \\
\text { Human }\end{array}$ & $\begin{array}{c}\text { Norovirus GV } \\
\text { (MW174170) } \\
\text { Norway Rat }\end{array}$ & $\begin{array}{c}\text { Norovirus GVI } \\
\text { (MN908340) } \\
\text { Dog }\end{array}$ \\
\hline $\begin{array}{l}\text { Complete } \\
\text { genome }\end{array}$ & 58.3 & 51.6 & 93.4 & 53.3 & 50.8 & 53.6 \\
\hline p48 & 53.1 & 44.9 & 92.8 & 46.8 & 45.3 & 47.5 \\
\hline NTPase & 64.7 & 55.1 & 94.3 & 56.1 & 53.2 & 58.3 \\
\hline p22 & 46.4 & 46.3 & 90.0 & 46.6 & 43.9 & 44.7 \\
\hline $\mathrm{VPg}$ & 55.1 & 53.3 & 92.1 & 55.7 & 52.7 & 58.6 \\
\hline Pro & 59.1 & 63.7 & 96.9 & 61.5 & 59.6 & 63.7 \\
\hline RdRp & 66.5 & 59.2 & 94.3 & 60.9 & 58.5 & 63.0 \\
\hline ORF2-VP1 & 56.2 & 49.2 & 93.3 & 51.1 & 50.2 & 52.3 \\
\hline ORF3-VP2 & 41.8 & 42.7 & 92.2 & 43.9 & 42.0 & 41.7 \\
\hline
\end{tabular}

\subsection{BoAstV Acquisition and Analysis}

A complete genome of BoAstV/CN/HB-SJZ/2021 was sequenced and assembled. The BoAstV/CN/HB-SJZ/2021 genome was identical to the genome sequence assembled from metagenomics data. The size of the genome was 6324 bases and the $\mathrm{G}+\mathrm{C}$ content was $52.25 \%$ (Table 2). The genome organization of BoAstV/CN/HB-SJZ/2021 was consistent with those of other BoAstV and deer astroviruses (deer AstVs), consisting of a $5^{\prime}$-UTR, three ORFs (ORF1a, ORF1b, and ORF2), and a 3'-UTR. The 5'-UTR and 3'-UTR consisted of 86 bases and 73 bases, respectively. The ORF2 of BoAstV/CN/HB-SJZ/2021 was predicted to encode a capsid protein of 767 amino acids. BoAstV/CN/HB-SJZ/2021 was most closely related to BoAstV/JPN/2013; it shared $86.0 \%$ nucleotide identity on the capsid protein (ORF2) region and was not so closely related to other Astrovirus species, including BoAstV B76-2/HK, BoAstV B18/HK, and Astrovirus Roe deer/SLO/D12-14, the three of which share $57.2 \%, 57.1 \%$, and $56.5 \%$ nucleotide identities, respectively (Table 4) (Figure 2). As for genogroup, BoAstV/CN/HB-SJZ/2021 is not clustered with either genogroup I or II. Instead, it is closely related to a few unclassified astroviruses, including a few BoAstV, yak astrovirus, and dromedary astroviruses, suggesting that BoAstV/CN/HB-SJZ/2021 may potentially constitute a new genogroup in the genus Mamastrovirus (Figure 2a).

Table 4. The nucleotide identities of BoAstV/CN/HB-SJZ/2021 compared to different astrovirus isolates.

\begin{tabular}{cccccccc}
\hline & \multicolumn{3}{c}{ Nucleotide Identity (\%) } \\
\hline & \multicolumn{3}{c}{ Mamastrovirus Undassified Genogroup } & \multicolumn{3}{c}{$\begin{array}{c}\text { Mamastrovirus Mamastrovirus } \\
\text { Genogroup I } \\
\text { Genogroup II }\end{array}$} \\
\cline { 2 - 8 } & $\begin{array}{c}\text { Bovine } \\
\text { (LC047787) }\end{array}$ & $\begin{array}{c}\text { Bovine } \\
\text { (HQ916317) }\end{array}$ & $\begin{array}{c}\text { Roe Deer } \\
\text { (MN150125) }\end{array}$ & $\begin{array}{c}\text { Bovine } \\
\text { (HQ916313) }\end{array}$ & $\begin{array}{c}\text { Porcine } \\
\text { (JF713713) }\end{array}$ & $\begin{array}{c}\text { Human } \\
\text { (NC_011400) }\end{array}$ & $\begin{array}{c}\text { Ovine } \\
\text { (NC_002469) }\end{array}$ \\
\hline Complete genome & 88.4 & 77.0 & 72.3 & 81.4 & 77.3 & 64.0 & 56.4 \\
ORF1ab & 95.8 & 87.7 & 80.9 & 73.3 & 52.9 & 44.9 & 46.0 \\
ORF2 & 86.0 & 57.2 & 56.5 & 57.1 & 46.5 & 38.9 \\
\hline
\end{tabular}



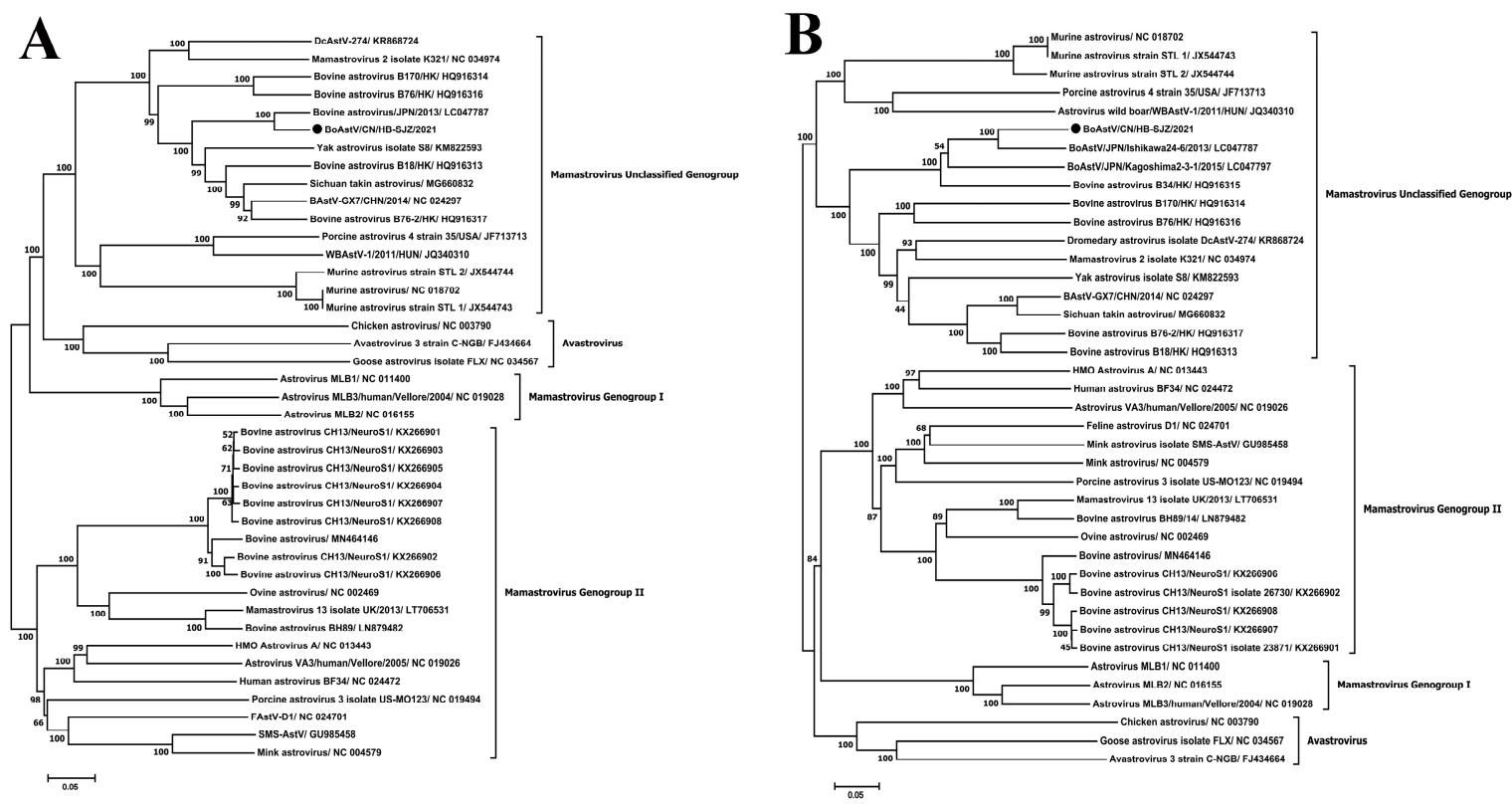

Figure 2. Phylogenetic analysis of BoAstV/CN/HB-SJZ/2021: (A) Neighbor-joining unrooted phylogenetic trees based on the nucleotide sequences of the full-length sequences of BoAstV/CN/HB-SJZ/2021 and different genogroups. (B) Neighborjoining unrooted phylogenetic trees based on the ORF2 sequences of BoAstV/CN/HB-SJZ/2021 and different genogroups. The bar represents a genetic distance. Numbers at nodes indicate bootstrap percentages obtained after 1000 bootstrap replicates. Our strain, BoAstV/CN/HB-SJZ/2021, is marked with a black circle $(\bullet)$.

\subsection{Discovery and Analysis of BKoV}

The BKoV we obtained by sequencing contained 8376 base genomes. The BKoV/CN/HBSJZ/2021 genome contained a large ORF, which encoded potential polyprotein precursors of 2568 amino acids. Reads were assembled into a complete genome contig that shares $88.4 \%$ nucleotide identity with the BKoV reference genome (MN336260), and genetic evolution analysis shows that the $\mathrm{BKoV} / \mathrm{CN} / \mathrm{HB}-\mathrm{SJZ} / 2021$ belongs to the Aichi virus B genus (Figure 3 ). The $2 \mathrm{C}$ region of $\mathrm{BKoV}$ is relatively conserved, with nucleotide similarity reaching $62.7-89.2 \%$. This region contains a highly conserved amino acid motif, GXXGXGKT, which is also recognized as the nucleic acid binding region of microRNA virus helicase. Therefore, $2 \mathrm{C}$ protein may be related to virus replication and nucleic acid uncoiling. There are three highly conserved amino acid motifs in the 3D region which encode the virus RNA polymerase. The nucleotide sequence similarity of the $3 \mathrm{D}$ region of the crest virus is the highest at $66.7-93.0 \%$ (Table 5).

Table 5. The nucleotide identities of BKoV/CN/HB-SJZ/2021 compared to different kobuvirus isolates.

\begin{tabular}{|c|c|c|c|c|c|c|c|c|c|c|}
\hline \multicolumn{11}{|c|}{ Nucleotide Identity (\%) } \\
\hline & \multicolumn{4}{|c|}{ Aichivirus A } & \multicolumn{3}{|c|}{ Aichivirus B } & \multirow{2}{*}{$\begin{array}{c}\begin{array}{c}\text { Aichivirus } \\
C\end{array} \\
\text { Porcine } \\
\text { (EU787450) }\end{array}$} & \multirow{2}{*}{$\begin{array}{c}\begin{array}{c}\text { European } \\
\text { Roller } \\
\text { Kobuvirus }\end{array} \\
\text { Coracias } \\
\begin{array}{c}\text { Garrulus } \\
\text { (KJ934637) }\end{array}\end{array}$} & \multirow{2}{*}{$\begin{array}{c}\begin{array}{c}\text { Caprine } \\
\text { Kobuvirus }\end{array} \\
\begin{array}{c}\text { Caprine } \\
\text { (KF793927) }\end{array}\end{array}$} \\
\hline & $\underset{\text { (AB010145) }}{\text { Human }}$ & $\begin{array}{l}\text { Canine } \\
\text { (MH747478) }\end{array}$ & $\begin{array}{c}\text { Feline } \\
\text { (KJ958930) }\end{array}$ & $\begin{array}{c}\text { Mouse } \\
\text { (JF755427) }\end{array}$ & $\begin{array}{l}\text { Bovine } \\
\text { (MN336260) }\end{array}$ & $\begin{array}{c}\text { Sheep } \\
\text { (GU245693) }\end{array}$ & $\begin{array}{c}\text { Ferret } \\
\text { (KF006985) }\end{array}$ & & & \\
\hline $\begin{array}{l}\text { Complete } \\
\text { genome }\end{array}$ & 58.4 & 58.7 & 58.5 & 58.4 & 88.4 & 81.4 & 77.3 & 64.0 & 56.4 & 64.3 \\
\hline P1 & 57.5 & 58.0 & 58.4 & 57.3 & 84.0 & 75.8 & 76.0 & 63.8 & 57.1 & 62.3 \\
\hline $2 \mathrm{C}$ & 68.1 & 68.0 & 65.9 & 65.6 & 89.2 & 85.9 & 82.4 & 72.0 & 62.7 & 70.5 \\
\hline $3 \mathrm{D}$ & 69.4 & 69.6 & 71.2 & 69.8 & 93.0 & 90.3 & 85.4 & 73.9 & 66.7 & 75.9 \\
\hline
\end{tabular}




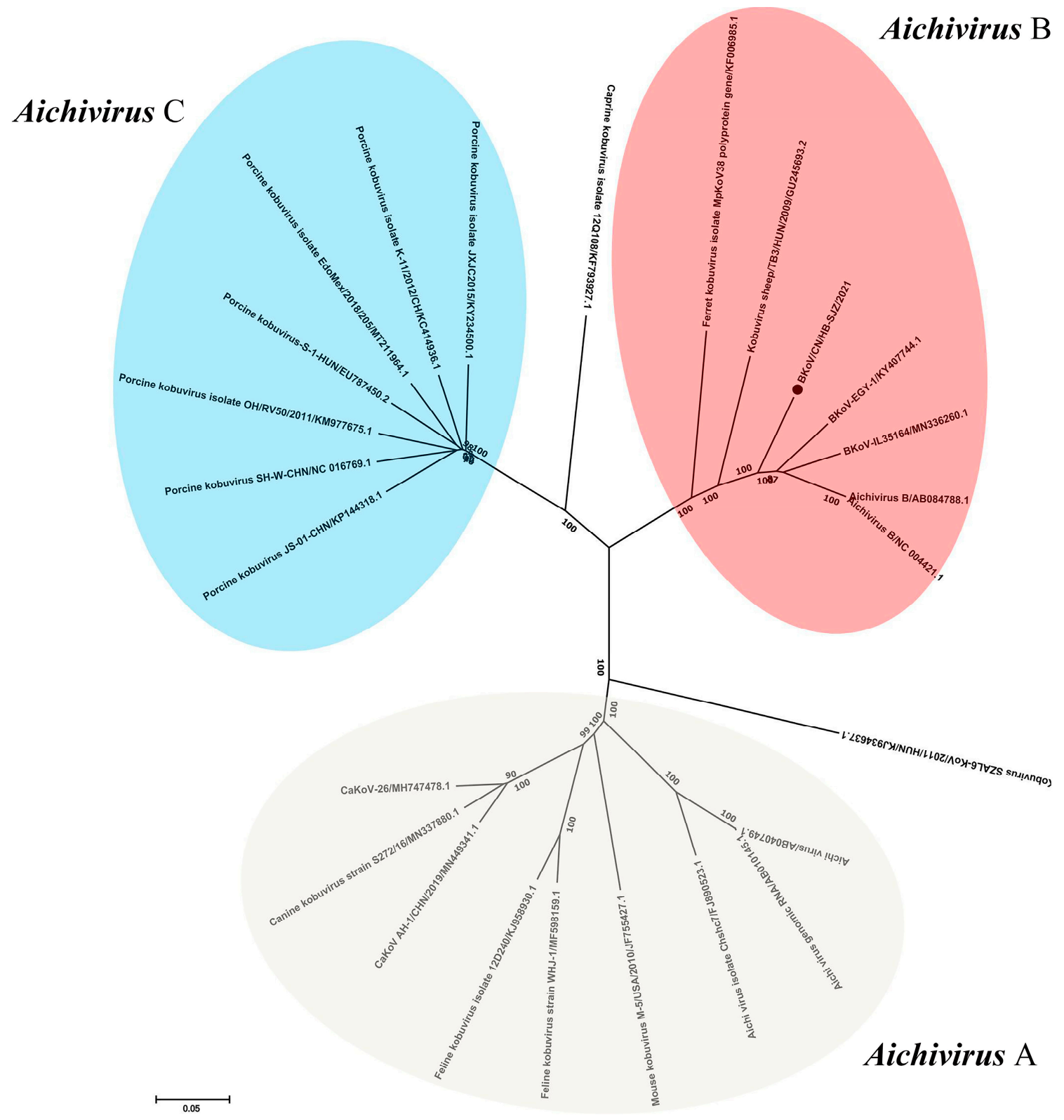

Figure 3. Phylogenetic analysis of BKoV/CN/HB-SJZ/2021: Neighbor-joining unrooted phylogenetic trees based on complete genomic sequences of $\mathrm{BKoV} / \mathrm{CN} / \mathrm{HB}-\mathrm{SJZ} / 2021$ and other genus aichiviruses. The bar represents a genetic distance. Numbers at nodes indicate bootstrap percentages obtained after 1000 bootstrap replicates. Our strain, BKoV/CN/HBSJZ/2021, is marked with a black circle $(\bullet)$.

\subsection{Analysis of the Coronavirus Genome}

After BLAST alignment, we assembled the complete $S$ gene sequence of $\mathrm{BCoV}$ through sequencing, and a sequence of $4092 \mathrm{nt}$ length was obtained, encoding 1363 amino acid. The BCoV S genes from different parts of the world were selected as reference sequences. The complete phylogenetic tree of the $S$ gene showed that, compared with the isolates from Vietnam and Cuba, the isolates formed a clear clade. In addition, BCoV-S/CN/HBSJZ/2021 sequences closely related to BCoV/CH/HB-BD/2019 (MK903506) (Figure 4), which encodes the $S$ protein, were identified $(99.6 \%)$. It shared a anucleotide sequence higher than $99.1 \%$ with the Chinese strain, $98.4 \%$ similarity with the Vietnamese strain, and only $93.7 \%$ homology with the human coronavirus (Table 6). Sequence alignment shows that there are 17 base mutations with MK903506, and 6 mutations in encoded amino acids. 


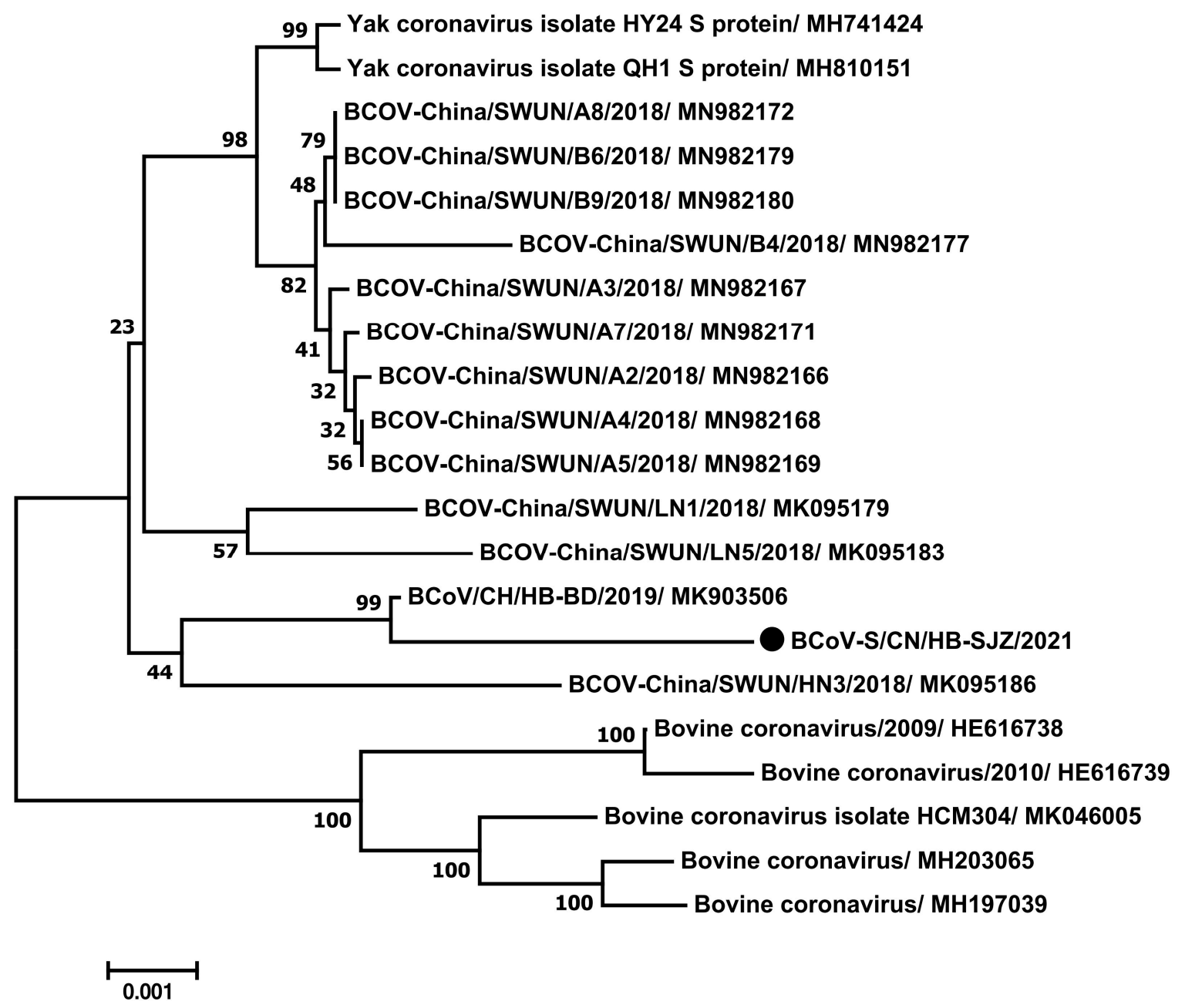

Figure 4. Phylogenetic analysis of BCoV/CN/HB-SJZ/2021: Neighbor-joining unrooted phylogenetic trees based on the S gene sequences of $\mathrm{BCoV} / \mathrm{CN} / \mathrm{HB}-\mathrm{SJZ} / 2021$ and other BCoV. The bar represented a genetic distance. Numbers at nodes indicate bootstrap percentages obtained after 1000 bootstrap replicates. Our strain, BKoV/CN/HB-SJZ/2021, is marked with a black circle $(\bullet)$.

Table 6. The nucleotide identities of BCoV/CN/HB-SJZ/2021 compared to different coronavirus isolates.

\begin{tabular}{cccccc}
\hline Organism & GenBank Accession No. & Host & Country & $\begin{array}{c}\text { Year } \\
\text { Nucleotide } \\
\text { Identity (\%) }\end{array}$ \\
\hline & MK903506 & Cattle & China & 2019 & 99.6 \\
BCoV & MK095179 & Cattle & China & 2018 & 99.1 \\
& MH197039 & Calf & Vietnam & 2017 & 98.4 \\
MH203065 & Calf & Vietnam & 2017 & 98.4 \\
Canine respiratory & AY150272 & Canine & The United Kingdom & 2002 & 95.8 \\
coronavirus & AB242262 & Canine & Japan & 2005 & 96.0 \\
& EU983107 & Canine & South Korea & 2008 & 95.8 \\
Human coronavirus OC43 & AY903454 & Human & Belgium & 2003 & 93.7 \\
& KF963234 & Human & France & 2003 & 93.7 \\
\hline
\end{tabular}

\section{Discussion}

Viral gastroenteritis remains as an important cause of morbidity and mortality in neonatal calves [8]. A considerable number of viruses in the gastrointestinal tract of calves are yet to be identified. Currently, the use of next-generation sequencing technologies facilitates virus detection and description. In this study, the metagenomics analysis revealed that four different viruses, $\mathrm{BCoV}, \mathrm{BoAst} \mathrm{V}, \mathrm{BKoV}$, and $\mathrm{BNoV}$, were present in feces from calf diarrhea, and the distribution of these viruses was each associated with calf diarrhea. 
Additionally, a level of co-infection was detected, and co-infection or a specific combination of viruses is more likely to result in calf diarrhea, and requires the analysis of a larger number of cases and controls. A recent study has shown the presence of five viruses, including $\mathrm{BToV}, \mathrm{BCoV}, \mathrm{BRoV}, \mathrm{BVDV}$, and small round structured viruses (SRSV) in the feces of dairy calves, with a rate of co-infection of $14 \%$ in diarrheic calves, suggesting that mixed infections are common in calf populations [17].

The astroviruses reported here are commonly associated with gastrointestinal disease, particularly in immunodeficient infants [18,19], and they are generally detected in fecal samples [20,21]. Moreover, astrovirus can also been detected in the brains of humans [22] and animals [23], including cows, showing with neurological symptoms [24,25]; this indicates that the host's range can extend beyond enteric tissues. However, the role of BoAstV as a causative agent of diarrhea in cattle is controversial and has not been extensively studied. Based on genomic sequences, ORF2 has greater variability among the three ORFs, and the characteristics of the ORF2 gene are important bases for AstV typing [26,27]. Analysis of the genetic evolution of the virus showed that, compared with other regions of the genome, the ORF2 region had the lowest similarity to other strains, which may suggest that a new serotype/genotype may appear. It is noteworthy that neonatal calf diarrhea is generally of a multifactorial origin; our study not only established an association between the presence of the virus and disease, but also determined the genetic diversity of BoAst $\mathrm{V}$ in herds from China.

$\mathrm{BCoV}$ has been associated with enteric and respiratory disease in cattle, including neonatal calf diarrhea (NCD) [28], winter dysentery (WD) [29], and respiratory tract illness [30]. All BCoV isolates identified so far that are shed in feces and nasal secretions belong to one serotype/genotype based on virus cross-neutralization and genotyping analyses, regardless of clinical origin [31]. However, there is no specific or effective method with which to prevent or control $\mathrm{BCoV}$ infection in China. In other countries, inactivated vaccines or attenuated vaccines are primarily used to immunize pregnant cows so that calves can ingest colostrum to improve passive immunity, or so that newborn calves can be used to stimulate active immunity [32]. However, a commercial $\mathrm{BCoV}$ vaccine was not available in China. S protein is a larger membrane glycoprotein that contains two hydrophobic regions and two subunits, S1 and S2, that are formed by cleavage at the 768 and 769 amino acids [33], which are mainly responsible for cell adhesion, blood coagulation, membrane fusion, and the induction of neutralizing antibodies. S1 is responsible for the recognition and binding of viruses and host cells, while S2 is related to the fusion between virus cells. The sequence comparison between BCoV-S/CN/HB-SJZ/2021 and its nearest strain, $\mathrm{BCoV} / \mathrm{CH} / \mathrm{HB}-\mathrm{BD} / 2019$ (MK903506), showed that there are six amino acid mutation sites, of which four amino acid mutation sites are in the $\mathrm{S} 1$ subunit and two are in the S2 subunit. This indicates that most of the mutations are in the S1 region, and we can conduct in-depth research on this identification and combination area in order to provide more data for vaccine development and drug design.

To date, the pathogenesis of $\mathrm{BNoV}$ has been poorly understood, and the prevalence of $\mathrm{BNoV}$ in cattle has not been well established. In our study, $\mathrm{BNoV}$ was identified as the co-infection pathogen from diarrheic samples, along with other pathogens. Therefore, the true role of $\mathrm{BNoV}$ as a primary pathogen or as a form of co-infection remains unclear. Based on the phylogenetic relationships inferred from the VP1 sequences, noroviruses have been divided into six genogroups (GI to GVI), and BNoV is classified as GIII. The strain identified in our study was BNoV-GIII 2. Considering the previously reported GIII.1 strains identified in China [34,35]. It can be inferred that both genotypes GIII.1 and GIII.2 related sequences that have been found to circulate in Chinese dairy calves. Due to the limited epidemiological data on $\mathrm{BNoV}$ infections in China, the dominant strains cannot be accurately confirmed. Moreover, while different genotypes co-exist, ways of preventing diarrhea caused by $\mathrm{BNoV}$ are unclear. The results of our study will facilitate further research on the evolution and molecular pathogenesis of $\mathrm{BNoV}$. 
In 2008, BKoV was isolated from fecal samples of cattle with diarrhea, and it was concluded that $\mathrm{BKoV}$ played a role in the pathogenesis of enteritis in calves. However, the role of $\mathrm{BKoV}$ infection in calf diarrhea still needs to be clarified because of the presence of this virus in clinically normal animals [5]. In this study, through homology comparison, we found that the P1 gene showed as highly variable, while the 3D gene was highly conserved. Many early studies have shown that the BKoV-3D gene is mainly used to distinguish $\mathrm{BKoV}$ from other kobuviruses in phylogeny, rather than to differentiate $\mathrm{BKoV}$ into different lineages [36,37]. Therefore, the 3D gene may be used for designing specific primers for BKoV detection.

In summary, this study provided important information on at least four viral pathogens detected in diarrheic samples. These results will certainly contribute to the understanding of the evolution and pathology of $\mathrm{BCoV}, \mathrm{BoAst} \mathrm{V}, \mathrm{BKoV}$, and $\mathrm{BNoV}$ in cattle. Further epidemiology studies will reveal whether these viruses can also be found in other diarrheic samples, as well as their pathogenic potentials. Next-generation sequencing, as a new method, can discover more unknown viruses in samples, better understand the causes of calf diarrhea, and provide powerful technical support for the prevention and control of diarrheal diseases.

Author Contributions: Q.W., J.L. and W.W. took part in all the experiments and wrote the manuscript. X.Z., D.S. and B.F. helped to design the whole project and draft the manuscript. J.Z. and D.W. conducted RNA isolation, RT-PCR detection, and sample processing for sequencing. S.S. and G.G. conducted data analysis. B.L. contributed essential ideas and discussion. All authors have read and agreed to the published version of the manuscript.

Funding: This work was supported by National Key Research and Development Program (2021YFD1 800014), National Natural Science Foundation of China (31802167, 31872481, and 31941013), Jiangsu province Natural Sciences Foundation (BK20190003, BK20191235), Jiangsu Agricultural Science and Technology Innovation Fund (CX (20) 3094), China Agriculture Research System of MOF and MARA (CARS-37), Key Projects of the Tibet Autonomous Region Science and Technology Department in 2019.

Institutional Review Board Statement: Not applicable.

Informed Consent Statement: Not applicable.

Data Availability Statement: All data used and presented in this study is either available in public repositories as described in the Methods section or is made available in NCBI database.

Conflicts of Interest: The authors declare that they have no competing interest. The funder had no role in the design of the study; in the collection, analyses, or interpretation of data; in the writing of the manuscript, or the decision to publish the results.

\section{References}

1. Candido, M.; Batinga, M.; Alencar, A.; Almei Da -Queiroz, S.D.; Buzinaro, M.G.; Livonesi, M.C.; Fernandes, A.M.; Sousa, R.D. Molecular characterization and genetic diversity of bovine Kobuvirus, Brazil. Virus Genes 2017, 53, 105-110. [CrossRef]

2. Cho, Y.I.; Yoon, K.J. An overview of calf diarrhea-infectious etiology, diagnosis, and intervention. J. Vet. Sci. 2014, 15, 1-17. [CrossRef] [PubMed]

3. Bendali, F.; Bichet, H.; Schelcher, F.; Sanaa, M. Pattern of diarrhoea in newborn beef calves in south-west France. Vet. Res. 1999, 30, 61-74. [PubMed]

4. Kirisawa, R.; Takeyama, A.; Koiwa, M.; Iwai, H. Detection of bovine torovirus in fecal specimens of calves with diarrhea in Japan. J. Vet. Med. Sci. 2007, 69, 471-476. [CrossRef] [PubMed]

5. Park, S.I.; Jeong, C.; Kim, H.H.; Park, S.H.; Park, S.J.; Hyun, B.H.; Yang, D.K.; Kim, S.K.; Kang, M.I.; Cho, K.O. Molecular epidemiology of bovine noroviruses in South Korea. Vet. Microbiol. 2007, 124, 125-133. [CrossRef] [PubMed]

6. Jeoung, H.Y.; Lim, J.A.; Jeong, W.; Oem, J.K.; An, D.J. Three clusters of bovine kobuvirus isolated in Korea, 2008-2010. Virus Genes 2011, 42, 402-406. [CrossRef]

7. Kailasan, S.; Halder, S.; Gurda, B.; Bladek, H.; Chipman, P.R.; McKenna, R.; Brown, K.; Agbandje-McKenna, M. Structure of an enteric pathogen, bovine parvovirus. J. Virol. 2015, 89, 2603-2614. [CrossRef]

8. Peter, S.G.; Gitau, G.K.; Richards, S.; Vanleeuwen, J.A.; Uehlinger, F.; Mulei, C.M.; Kibet, R.R. Risk factors associated with Cryptosporidia, Eimeria, and diarrhea in smallholder dairy farms in Mukurwe-ini Sub-County, Nyeri County, Kenya. Vet. World 2016, 9, 811-819. [CrossRef] 
9. Gomez, D.E.; Weese, J.S. Viral enteritis in calves. Can. Vet. J. 2017, 58, 1267-1274.

10. Belak, S.; Karlsson, O.E.; Blomstrom, A.L.; Berg, M.; Granberg, F. New viruses in veterinary medicine, detected by metagenomic approaches. Vet. Microbiol. 2013, 165, 95-101. [CrossRef]

11. Delwart, E. A roadmap to the human virome. PLoS. Pathog. 2013, 9, e1003146. [CrossRef]

12. Miller, M.B.; Tang, Y.W. Basic concepts of microarrays and potential applications in clinical microbiology. Clin. Microbiol. Rev. 2009, 22, 611-633. [CrossRef]

13. Streit, W.R.; Schmitz, R.A. Metagenomics-The key to the uncultured microbes. Curr. Opin. Microbiol. 2004, 7, 492-498. [CrossRef] [PubMed]

14. Chan, J.Z.; Sergeant, M.J.; Lee, O.Y.; Minnikin, D.E.; Besra, G.S.; Pap, I.; Spigelman, M.; Donoghue, H.D.; Pallen, M.J. Metagenomic analysis of tuberculosis in a mummy. N. Engl. J. Med. 2013, 369, 289-290. [CrossRef] [PubMed]

15. Guan, T.P.; Teng, J.L.L.; Yeong, K.Y.; You, Z.Q.; Liu, H.; Wong, S.S.Y.; Lau, S.K.P.; Woo, P.C.Y. Metagenomic analysis of Sichuan takin fecal sample viromes reveals novel enterovirus and astrovirus. Virology 2018, 521, 77-91. [CrossRef] [PubMed]

16. Ng, T.F.; Kondov, N.O.; Deng, X.; Van Eenennaam, A.; Neibergs, H.L.; Delwart, E. A metagenomics and case-control study to identify viruses associated with bovine respiratory disease. J. Virol. 2015, 89, 5340-5349. [CrossRef] [PubMed]

17. Chiu, C.Y. Viral pathogen discovery. Curr. Opin. Microbiol. 2013, 16, 468-478. [CrossRef]

18. Duckmanton, L.; Carman, S.; Nagy, E.; Petric, M. Detection of bovine torovirus in fecal specimens of calves with diarrhea from Ontario farms. J. Clin. Microbiol. 1998, 36, 1266-1270. [CrossRef]

19. Afrad, M.H.; Karmakar, P.C.; Das, S.K.; Matthijnssens, J.; Ahmed, F.; Nahar, S.; Faruque, A.S.; Rahman, M.Z.; Rahman, M.; Azim, T. Epidemiology and genetic diversity of human astrovirus infection among hospitalized patients with acute diarrhea in Bangladesh from 2010 to 2012. J. Clin. Virol. 2013, 58, 612-618. [CrossRef]

20. Guix, S.; Bosch, A.; Pinto, R.M. Human astrovirus diagnosis and typing: Current and future prospects. Lett. Appl. Microbiol. 2005, 41, 103-105. [CrossRef] [PubMed]

21. Li, L.; Shan, T.; Wang, C.; Cote, C.; Kolman, J.; Onions, D.; Gulland, F.M.; Delwart, E. The fecal viral flora of California sea lions. J. Virol. 2011, 85, 9909-9917. [CrossRef] [PubMed]

22. Shan, T.; Li, L.; Simmonds, P.; Wang, C.; Moeser, A.; Delwart, E. The fecal virome of pigs on a high-density farm. J. Virol. 2011, 85, 11697-11708. [CrossRef] [PubMed]

23. Quan, P.L.; Wagner, T.A.; Briese, T.; Torgerson, T.R.; Hornig, M.; Tashmukhamedova, A.; Firth, C.; Palacios, G.; Baisre-De-Leon, A.; Paddock, C.D.; et al. Astrovirus encephalitis in boy with X-linked agammaglobulinemia. Emerg. Infect. Dis. 2010, 16, 918-925. [CrossRef]

24. Blomstrom, A.L.; Widen, F.; Hammer, A.S.; Belak, S.; Berg, M. Detection of a novel astrovirus in brain tissue of mink suffering from shaking mink syndrome by use of viral metagenomics. J. Clin. Microbiol. 2010, 48, 4392-4396. [CrossRef] [PubMed]

25. Bouzalas, I.G.; Wuthrich, D.; Walland, J.; Drogemuller, C.; Zurbriggen, A.; Vandevelde, M.; Oevermann, A.; Bruggmann, R.; Seuberlich, T. Neurotropic astrovirus in cattle with nonsuppurative encephalitis in Europe. J. Clin. Microbiol. 2014, 52, 3318-3324. [PubMed]

26. Li, L.; Diab, S.; McGraw, S.; Barr, B.; Traslavina, R.; Higgins, R.; Talbot, T.; Blanchard, P.; Rimoldi, G.; Fahsbender, E.; et al. Divergent astrovirus associated with neurologic disease in cattle. Emerg. Infect. Dis. 2013, 19, 1385-1392. [CrossRef]

27. Lewis, T.L.; Greenberg, H.B.; Herrmann, J.E.; Smith, L.S.; Matsui, S.M. Analysis of astrovirus serotype 1 RNA, identification of the viral RNA-dependent RNA polymerase motif, and expression of a viral structural protein. J. Virol. 1994, 68, e53-e57. [CrossRef]

28. Velázquez-Moctezuma, R.; Baños-Lara, M.d.R.; Acevedo, Y.; Méndez, E. Alternative cell lines to improve the rescue of infectious human astrovirus from a cDNA clone. J. Virol. Methods 2012, 179, 295-302. [CrossRef]

29. Snodgrass, D.R.; Terzolo, H.R.; Sherwood, D.; Campbell, I.; Menzies, J.D.; Synge, B.A. Aetiology of diarrhoea in young calves. Vet. Rec. 1986, 119, 31-34. [CrossRef] [PubMed]

30. Saif, L.J.; Brock, K.V.; Redman, D.R.; Kohler, E.M. Winter dysentery in dairy herds: Electron microscopic and serological evidence for an association with coronavirus infection. Vet. Rec. 1991, 128, 447-449. [CrossRef]

31. Storz, J.; Lin, X.; Purdy, C.W.; Chouljenko, V.N.; Kousoulas, K.G.; Enright, F.M.; Gilmore, W.C.; Briggs, R.E.; Loan, R.W. Coronavirus and Pasteurella infections in bovine shipping fever pneumonia and Evans' criteria for causation. J. Clin. Microbiol. 2000, 38, 3291-3298. [CrossRef]

32. Suzuki, T.; Otake, Y.; Uchimoto, S.; Hasebe, A.; Goto, Y. Genomic Characterization and Phylogenetic Classification of Bovine Coronaviruses Through Whole Genome Sequence Analysis. Viruses 2020, 12, 183. [CrossRef] [PubMed]

33. Theil, K.W.; Mccloskey, C.M. Rotavirus shedding in feces of gnotobiotic calves orally inoculated with a commercial rotaviruscoronavirus vaccine. J. Vet. Diagn. Investig. 1995, 7, 427. [CrossRef] [PubMed]

34. Yoo, D.; Deregt, D. A Single Amino Acid Change within Antigenic Domain II of the Spike Protein of Bovine Coronavirus Confers Resistance to Virus Neutralization. Clin. Diagn. Lab. Immunol. 2001, 8, 297-302. [CrossRef] [PubMed]

35. Guo, Z.; He, Q.; Hua, Y.; Zhang, B.; Cheng, T. First detection of Nebovirus and Norovirus from cattle in China. Arch. Virol. 2018, 163, 475-478. [CrossRef] [PubMed]

36. Park, S.J.; Kim, H.K.; Song, D.S.; Moon, H.J.; Park, B.K. Molecular detection and genetic characterization of kobuviruses in fecal samples collected from diarrheic cattle in Korea. Infect. Genet. Evol. 2011, 11, 1178-1182.

37. Barry, A.F.; Ribeiro, J.; Alfieri, A.F.; Poel, W.; Alfieri, A.A. First detection of kobuvirus in farm animals in Brazil and the Netherlands. Infect. Genet. Evol. 2011, 11, 1811-1814. [CrossRef] 